\title{
Technological and institutional lock-in and excessive synthetic nitrogen fertilizer use on North American grain and oilseed farms
}

\author{
Luke Struckman \\ Department of Geography and Environmental Studies, Carleton University, Canada, \\ lukestruckman@gmail.com
}

\begin{abstract}
This intervention examines commodity grain and oilseed farmers' over reliance on synthetic nitrogen fertilizer in North America. Most grain and oilseed farmers apply synthetic nitrogen fertilizer at rates higher than necessary in order to ensure maximum yields. At the same time, high fertilizer application rates lead to increased farm input expenses and generate significant amounts of water pollution and excessive greenhouse gas emissions. A number of low-cost alternative approaches have been developed which can significantly reduce or eliminate the need for synthetic nitrogen fertilizer while maintaining farm profitability. But such practices have only seen limited adoption by Canadian and US farmers. This is despite significant production cost savings and environmental benefits. A number technological and institutional factors work in combination to lock farmers into production models requiring large amounts of synthetic nitrogen fertilizer. They include crop varieties bred to thrive in artificially high nitrogen soil conditions, conventional tillage practices, restrictive financial arrangements, largely unenforced water quality laws, and non-diverse marketing outlets. These technological and institutional lock-ins are significant barriers to the adoption of alternative crop production practices that are less reliant upon synthetic nitrogen fertilizer.
\end{abstract}

Keywords: synthetic nitrogen fertilizer, technological and institutional lock-in, farm profitability, fertilizer management, soil health

\section{Introduction}

Following the Second World War, grain and oilseed production in North America quickly transitioned to a high input/high output model developed through partnerships between government agencies and agribusiness. This high input/high output grain and oilseed production model became the norm in the more developed world during the late 1940s and 1950s and was pushed to many parts of the less developed world during the 1960s and 1970s (Smil 2005). The use of high input/high output systems over the past 75 years has led to consistent grain and oilseed yield gains worldwide, year after year. Synthetic nitrogen fertilizer is a central component of high input/high output agricultural systems and its incorporation into food production systems is lauded as key technological development in the quest for global food security. This perspective is common amongst those working in agriculture as well as in academic disciplines like agronomy, international development studies, and geography (Borlaug 1968; Parayil 2003; Moseley 2017; Norton \& Mercier 2019; Emch et al. 2017) 
However, this perspective rarely acknowledges the heavy financial and environmental costs of synthetic nitrogen fertilizer use. This perspective also shows a poor engagement with recent innovations in fertilizer management and soil health which have clearly demonstrated that acceptable yields of grains and oilseeds are attainable with significantly reduced amounts of synthetic fertilizer. Although technologically superior crop production practices are relatively easy and inexpensive to implement, most North American grain and oilseed farmers are technologically and institutionally locked into high-input/ high-output production systems that require large amounts of synthetic fertilizer.

\section{The use of synthetic nitrogen fertilizer in grain and oilseed production systems}

Grain and oilseed farming represents a significant economic activity across large parts of Canada and the United States. Grain and oilseed farms account for approximately $30 \%$ of farm acreage in Canada and $25 \%$ of farm acreage in the United States (Statistics Canada 2017; USDA 2020b). Major grain and oilseed crops grown in North America include canola, soy, sunflowers, cotton (where oil is extracted from the seeds after they have been separated from the cotton boll), corn, rice, and wheat. The flour, starch, oil and meal derived from these commodity crops have a wide range of uses which include processed food ingredients, edible oils and starches, animal feed, biofuels, bioplastics, and lubricants. Uniform characteristics, long storage life, and ease of transport make commodity grains and oilseeds ideal industrial feedstocks (Oliviera \& Hecht 2016).

The production of grains and oilseeds has the potential to be profitable for farmers (Statistics Canada 2014; USDA 2020a). But there are significant factors which make producing grains and oilseeds a risky venture. These include chronically depressed commodity prices (due to global oversupply), high farm input and operating costs, and increasingly erratic weather patterns as a result of anthropogenic climate change. Risk can be mitigated in a number of ways, such as through pre-season production contracts to guarantee crop marketing prices and crop insurance. Another way to mitigate risk is to maximize crop yields. A complex mix of growing conditions, farmer expertise, and luck determine crop yields in any given year. In the high input/ high output model that characterizes North American grain and oilseed production, synthetic nitrogen fertilizer plays a significant role in determining crop yields. It is also one factor that farmers have complete control over. Synthetic nitrogen fertilizer is sold as a liquid, pellets, or compressed gas - all of which can be easily applied at planting time or at various points in the growing season. Thus, the overapplication of synthetic nitrogen fertilizer can be seen as one way of minimizing risk through the maximization of crop production.

Unlike the soil macronutrients of phosphorus and potassium, nitrogen levels in soils can vary widely throughout the growing season and from year to year. Levels of bioavailable nitrogen in soils depend on factors related to soil properties, weather conditions, precipitation, nutrient cycling, and fertilizer applications in previous years. Soil sampling is one of the most reliable ways to determine soil nitrogen levels. 
However, the grid or zone soil sampling required to produce an accurate picture of soil nitrogen levels across broadacre cash crop fields is labor intensive and costly. This means that soils are rarely sampled at the temporal and spatial intensity needed to give farmers a baseline understanding of soil nitrogen levels at critical points in the growing season.

Nitrogen's role in producing high crop yields combined with the inherent difficulties of measuring soil nitrogen levels means that synthetic nitrogen is often applied at rates higher than necessary. While overapplication of synthetic nitrogen fertilizer may make sense from a crop production standpoint, there are significant problems associated with approaching soil fertility in such a manner. These include excessive farm input expenses, water pollution, and excessive greenhouse gas emissions.

Synthetic nitrogen fertilizer is a significant expense in a grain and oilseed farm's annual operating budget. In Canada, commercial fertilizer represents approximately $8.5 \%$ of a farm's annual expenses (Dorf \& Beaulieu 2014). In the United States, commercial fertilizer represents approximately $20 \%$ of a farm's annual expenses (USDA 2018). The heavy use of synthetic nitrogen fertilizer only adds to high production costs related to other synthetic chemical inputs like pesticides, herbicides, and fungicides. Once applied to the surface of a field, between $50 \%$ and $90 \%$ of synthetic nitrogen fertilizer becomes unavailable for cash crop plant uptake in the particular growing season it is applied. This is due to immobilization within the soil or migration from the soil root zone due to volatilization or leaching (Malhi et al. 2001). This loss can represent a significant amount of wasted capital in a farm's annual operating budget.
Considering the tight profit margins of most grain and oilseed farms, the amount of loss associated with such a costly input impedes the financial viability of farm operations.

In addition to wasted capital, synthetic nitrogen fertilizer is a significant non-point source of water pollution in grain and oilseed producing areas of Canada and the United States. Nitrogen leached from agricultural soils eventually ends up in surface water bodies and aquifers. Nitrogen pollution can contaminate drinking water supplies and long-term exposure contributes to a range of human health issues (Ward et al. 2018). Excess nitrogen runoff causes anoxic conditions in streams, rivers, lakes, estuaries, and coastal zones and has significant impacts on their ecological function. While summer season dead zones in Lake Erie and the Gulf of Mexico garner a great deal of media attention, excess nitrogen pollution is an issue affecting surface water bodies across grain and oilseed producing areas in North America.

Outside of synthetic nitrogen fertilizer's contribution to water pollution, it is a significant source of greenhouse gases like nitrous oxide, carbon dioxide, and methane. After synthetic nitrogen fertilizer is applied, it is broken down by soil microbes into nitrous oxide. Nitrous oxide emissions from soils are a normal byproduct of the nitrogen cycle. However, the application of synthetic nitrogen fertilizer to grain and oilseed fields results in nitrous oxide emissions far exceeding emission levels found in non-agricultural ecosystems and low-input agroecosystems. Nitrous oxide is a potent greenhouse gas that is long-lived in the atmosphere. The production of synthetic nitrogen fertilizer uses large amounts of natural gas, both as an energy source for 
production and as a feedstock. Carbon dioxide and methane emissions resulting from the fertilizer production process are significant and most likely are underreported (Zhou et al. 2019).

Advocates of the high input/high output agricultural systems that are used for North American grain and oilseed production argue that synthetic nitrogen is key to maintaining and increasing oilseed and grain yields. However, a number of methods have been developed which can be used to significantly reduce or eliminate the need for synthetic nitrogen fertilizer - while keeping grain and oilseed yields at profitable levels. The next section discusses these methods.

\section{Fertilizer management and soil health}

One fertilizer management method, known as "N-Rich strips", involves monitoring crop fertilizer requirements during the growing season. An in-field check strip receives a higher rate of fertilizer than the rest of the field. NDVI readings are taken in the check strip and other sample points in the field at predetermined intervals during the growing season. The only equipment required is a low-cost handheld NDVI sensor. Crop fertilizer requirements during the growing season can be determined by comparing NDVI readings between the check the strip and the rest of the field (Raun et al. 2017).

Another low-cost method for reducing synthetic nitrogen fertilizer use is GIS/ GPS-based Variable Rate Application (VRA) fertilizer systems. In a VRA system, geospatial information is gathered on a number of data points such as previous years' crop yields, landscape position, and soil characteristics. Using layered geospatial information, a zone map can be generated to prescribe zone-appropriate levels of nitrogen to be applied across the surface of a field throughout the growing season (Ess et al. 2001). While VRA systems require an investment in equipment and training, they are reasonably low-cost and easy to use after more than 15 years on the market. The advantages to methods like N-Rich and VRA is that they can account for dynamic nitrogen levels available in the soil throughout the growing season and from year to year. There is usually no yield penalty associated with their use and yields can even increase in some cases. Importantly, farmers can see significant cost savings and environmental benefits thanks to reduced synthetic nitrogen use.

Methods like N-Rich strips and VRA have been proven to help make fertilizer applications more effective. But they focus solely on fertilizer application management. In contrast, soil health management practices promote a more holistic approach to managing soil fertility. The concept of 'soil health' is gaining currency amongst conventional, regenerative, and organic farmers and is representative of a renewed interest in soil management strategies in North America. Soil health practices focus on improving soil biological, chemical and physical functions in relation to agricultural production (Wang 2020). As a result of improved soil function, synthetic fertilizer applications can be significantly reduced or even eliminated. Grain and oilseed yields are often slightly reduced through the use of soil health practices. But at the same time, the reduction in synthetic fertilizer costs compensates for lower yields.

Soil health practices include the use of no-till, cover cropping, increased cash crop 
and cover crop diversity, the maintenance of year-round soil cover with dead or living plant matter, and the grazing of livestock on cash crop residue and cover crops. Any one of these practices are considered beneficial on their own. However, the more of these practices that are implemented in combination, the better soils will function (Union of Concerned Scientists 2017). Soil health practices are not new and were widely used prior to the advent of high input agriculture following the Second World War. However, improvements to agricultural equipment and technology (such as purpose-built no-till planting equipment, GPS-based precision farming, or solar electric fencing hardware) make soil health practices easier and less costly to implement than they were in the past.

Soil health practices are highly specific to every farm operation and climate. Short growing seasons and high amounts of precipitation in grain and oilseed producing regions north of the $45^{\text {th }}$ parallel can be a limiting factor in the use of no-till, cover crops, and livestock grazing. Additionally, farmers in arid climates west of the $100^{\text {th }}$ meridian have fewer options regarding cover crops due to limited precipitation. Despite limiting climatic factors, soil health practices can be adapted to fit most farm operations and climates. Due to the highly-context specific nature of soil health practices, farmers themselves are largely responsible for the advances made during the past 15-20 years (Riley 2020; Rosenzweig \& Schipanski 2018).

Soil health practices are promoted by a range of governmental and non-governmental organizations in North America (Ontario Ministry of Agriculture, Food, and Rural Affairs 2016; USDA 2015; Union of Concerned Scientists 2017). Soil health practices align closely with Conservation Agriculture guidelines promoted by the UN Food and Agriculture Organization. In some important ways, soil health practices resemble methods developed by indigenous peoples to improve agricultural soil function (UNFAO 2020; Erickson 2008; Fairhead \& Leach 1996; Reij 2014).

Simple fertility management practices like N-Rich and VRA and more holistic soil health practices have been proven to significantly reduce or eliminate synthetic fertilizer use in the production of grains and oilseeds. If these methods discussed were to be adopted in various fashions across grain and oilseed producing landscapes in Canada and the United States, the monetary savings and pollution reductions would be significant. Despite clear financial and environmental benefits, fertility management and/or soil health practices are only being implemented in a scattershot fashion by a relatively small number of farmers. This is can be attributed to technological and institutional barriers that can be very difficult for farm operations to overcome on an individual basis, which will be discussed next.

\section{Technological and institutional lock-in}

The vast majority of grain and oilseed farmers utilize commercial crop varieties developed by large seed companies. These commercial crop varieties are hybrids and include the four primary GMO crops in production (corn, soy, cotton, and canola). The one exception to the widespread use of hybrid crop varieties are small grains like wheat and barley. Commercial grain and oilseed varieties have the ability to produce higher yields than comparable 
open-pollinated varieties. Many commercial varieties have traits that confer herbicide and insect pest resistance - such as glyphosate resistant soybeans or Bt corn. Herbicide and insect pest resistant GMO traits have helped to significantly reduce herbicide and pesticide use since they were introduced in the mid-1990s.

But commercial grain and oilseed varieties have some distinct disadvantages in relation to nutrient uptake. First, commercial varieties are developed by plant breeders in nitrogen rich environments. This results in plants with unintentionally selected traits that require large amounts of nitrogen in order to produce acceptable yields. Secondly, grain and oilseed plant breeders select plants for above ground traits like starch and oil content in seeds or standability at crop maturity. This means that many varieties of contemporary grains and oilseeds lack genetics conferring robust root structure associated with maximum nutrient uptake. As a result, commercial varieties have poor root structure when compared to older crop varieties and wild relatives (Kallenbach et al. 2016; Lynch 2018).

The high nitrogen requirements and poor root structure of commercial grain and oilseed varieties could be overcome by changing plant breeding conditions which better reflect crop production conditions as well as through the selection of crop varieties with lower nitrogen requirements and more robust root structures. High nitrogen conditions and the lack of attention to root development became the prevalent grain and oilseed breeding model worldwide during the latter half of the twentieth century and this model shows no signs of changing in the near term (Borlaug 1968; Crews et al. 2019).
The root characteristics and high nitrogen requirements of commercial grain and oilseed varieties is compounded by conventional tillage practices. While practices like no-till are prevalent on a significant number of acres on the Canadian prairies and strip-till has become more common in the US corn belt over the past decade, conventional tillage remains a prevalent form of soil management in most grain and oilseed producing areas of North America (Statistics Canada 2011; Classen et al. 2018). In conventional tillage systems, the upper layers of soil are frequently cultivated to address short-term agronomic and soil management issues like weed control and poor soil structure.

While conventional tillage does have short-term benefits, it has been shown to be a primary impediment to long-term agricultural soil function. As a result, grain and oilseed crops grown in soils managed with conventional tillage are unable to uptake significant amounts of synthetic nitrogen applied during the growing season. Despite problems with conventional tillage, it remains a prominent part of the agricultural landscape due to cultural values associated with tillage and the less-intensive management requirements of conventional tillage systems (Beck 2017).

High nitrogen requirements and poor root characteristics of commercial grain and oilseed varieties and the prominent use of conventional tillage represent major technological barriers to the reduction of synthetic nitrogen use in the production of grains and oilseeds. These barriers can be overcome from a technical standpoint and innovative farmers have found ways around them. However, there are broader institutional factors that continue to promote the application of high rates of nitrogen 
fertilizer. Institutional lock-in that perpetuates the continued use of large amounts of synthetic fertilizer can be attributed to landowner/tenant agreements, bank loans, crop insurance, highly uneven and often unenforced water quality laws, and non-diverse cash crop and livestock markets.

Landowner/tenant agreements, bank loans, and government-subsidized crop insurance structure farm cash flows and reflect the capital-intensive nature of grain and oilseed production. All three factors dictate how grain and oilseed crops are produced in order to minimize financial risk. Due to the high cost of agricultural land, grain and oilseed farmers often rent significant parts of their farms from non-farming landowners. Agricultural landowners are notoriously risk averse and hope to see consistent returns from their land assets (National Sustainable Agriculture Coalition 2015; Statistics Canada 2016). Next, most grain and oilseed farms must borrow significant amounts money from banks for fixed assets like land and equipment as well taking out annual operating loans for items like seed, inputs, and labor costs. Finally, crop insurance companies, like other insurance companies, are notoriously risk-averse $(\mathrm{Na}$ tional Resources Defense Council 2017).

For landowners, banks, and insurance companies, the surest way to guarantee financial returns and/or minimize financial risk is to use grain and oilseed production systems that maximize crop yields. As previously stated, the application of large amounts synthetic nitrogen fertilizer is one of the most significant factors in determining crop yields. However, not all farm operations are highly leveraged and are not subject to the restrictions of these institutions. At the same time a small but growing number of landowners, banks, and insurance companies are recognizing that conventional grain and oilseed production systems requiring large amounts of nitrogen fertilizer are becoming obsolete in an era of low commodity prices and worldwide grain and oilseed overproduction.

Outside of these financial restrictions, water quality laws are highly uneven and unenforced in most grain and oilseed growing areas in North America. This permissive legal stance allows for pollution with no legal or monetary ramifications for farmland owners. Additionally, pollution caused by synthetic fertilizer run-off is non-point source, making enforcement extremely difficult. While some jurisdictions have made progress in passing and enforcing stringent water quality laws, water pollution legislations is permissive and rarely enforced in the vast majority of grain and oilseed producing areas of North America (Schwartz 2020).

Finally, non-diverse cash crop and livestock markets continue to favor the production of a small set of grain and oilseed crops and cattle as the only grazing ruminants in grain and oilseed producing areas. Limited market outlets are a significant barrier to implementing holistic soil health practices because it can be very difficult to connect best practices in soil health (i.e. cash crop and livestock diversity) with narrow cash crop and livestock market demands (Roesch-McNally et al. 2018).

\section{Conclusion}

Advocates of high input/high output agricultural systems argue that large amounts of synthetic nitrogen fertilizer are essential to the production of grains and oilseeds. While the yields produced by these systems 
in North America are impressive, they come at high financial and environmental costs. Significant amounts of farm financial resources are dedicated to purchasing fertilizer while grain and oilseed producing areas suffer from poor water quality and play a large role in greenhouse gas emissions. While viable methods of fertilizer management and soil health have been developed which have been proven to reduce or eliminate the need for synthetic nitrogen fertilizer, their uptake by farmers has been slow. Technological and institutional lock-in has prevented technologically (and financially) superior ways of managing cash crop nitrogen requirements from being adopted more widely. Due to the significant amount of land dedicated to grain and oilseed farming in North America, changes to fertilizer and soil management could have significant impacts on farm financial viability as well as water pollution and greenhouse gas emissions related to grain and oilseed production.

\section{References}

Beck, D. (2017). Cover Crop Establishment and Grazing. https://www.youtube.com/watch?v=4m2ukTxaHek (48:08).

Borlaug, N. (1968). Wheat breeding and its impact on world food supply. In K. W. Finlay \& K. W. Shepherd (eds.): Proceedings of the Third International Wheat Genetics Symposium, 1-36. Canberra: Australian Academy of Science.

Classen, R., M. Bowman, J. McFadden, D. Smith, \& S. Wallander (2018). Tillage Intensity and Conservation Cropping in the United States. USDA Economic Information Bulletin Number 197. https://www.ers.usda.gov/webdocs/publications/90201/eib-197.pdf?v=7027.1.

Crews, T., W. Carton \& L. Olsson. (2018). Is the future of agriculture perennial? Imperatives and opportunities to reinvent agriculture by shifting from annual monocultures to perennial polycultures. Global Sustainability 1: 11, 1-18.
Dorf, E. \& M. Beleiu (2012). Canadian Agriculture at a Glance: Feeding the Soil Puts Food on Your Plate. Statistics Canada Analytical Paper. https://www150.statcan.gc.ca/n1/en/ pub/96-325-x/2014001/article/13006-eng.pdf?st=Sbvon480.

Emch, M., E. Root, \& M. Carrel (2017). Health and Medical Geography: Fourth Edition. New York: Guilford Press.

Erickson, C.L. (2008). Amazonia: The Historical Ecology of a Domesticated Landscape. In $\mathrm{H}$. Silverman \& W.H. Isbell (eds.): The Handbook of South American Archaeology, 157-183. New York: Springer.

Ess, D., M. Morgan \& S. Parsons (2001). Implementing Site-Specific Management: Map Versus Sensor-based Variable Rate Application. https:// www.extension.purdue.edu/extmedia/AE/SSM2-W.pdf.

Fairhead, J. \& M. Leach (1995). False Forest Histories, Complicit Social Analysis: Rethinking Some West African Environmental Narratives. World Development 23:6, 1023-1035.

Lynch, J. (2018). Rightsizing root phenotypes for drought resistance. Journal of Experimental Botany 69:13, 3279-3292.

Malhi, S., C. Grant, A. Johnston, \& K. Gill, (2001) Nitrogen fertilization management for no-till cereal production in the Canadian Great Plains: A review. Soil and Tillage Research. 60: 3-4, 101-122.

Moseley, W.G. (2017). A risky solution for the wrong problem: Why GMOs won't feed the hungry of the world. The Geographical Review 107:4, 578-583.

National Resources Defense Council (2017). Covering crops: How Federal crop insurance program reforms can reduce costs, empower farmers, and protect natural resources.https://www.nrdc. org/sites/default/files/federal-crop-insurance-program-reforms-ip.pdf.

National Sustainable Agriculture Coalition (2015). Who Owns U.S. Farmland and How Will it Change? https://sustainableagriculture.net/blog/ total-2014-results/.

Nestle, M. (2012). The Exceedingly Strange World of Federal Crop Insurance Subsidies. The Atlantic Monthly, 16 April 2012. https://www.theatlantic. com/health/archive/2012/04/the-exceedingly-strange-world-of-federal-crop-insurance-subsidies/255989/.

Norton, W. \& M. Mercier (2019). Human Geography (10th edition). Oxford: Oxford University Press.

Nunn, S. (2018). "U.S. Farmers Are Producing Too Much Food. Here's Why They Can't Stop." The Wall Street Journal, 5 February 2018. https:// blogs.wsj.com/economics/2018/02/05/u-s-farm- 
ers-are-producing-too-much-food-heres-whythey-cant-stop/.

Raun, B., J. Solie, J. May, H. Zhang, J. Kelly, R. Taylor, B. Arnall \& I. Ortiz-Monasterio (2017) Nitrogen Rich Strips for Wheat, Corn and Other Crops. http://www.nue.okstate.edu/Index_Publications/ Nstrip\%20brochure.pdf.

Riley, S. (2020). Meet the Canadian farmers fighting climate change. The Narwhal, 5 September 2020. https://thenarwhal.ca/canadian-farmers-climate-change/.

Oliviera, G. \& S. Hecht. (2016). Sacred groves, sacrifice zones and soy production: globalization, intensification and neo-nature in South America. The Journal of Peasant Studies 43:2, 251-285.

Ontario Ministry of Agriculture, Food, and Rural Affairs (2016). Best Management Practices: Soil Health in Ontario. http://www.omafra.gov.on.ca/ english/environment/bmp/AF151.pdf.

Parayil, G. (2003). Mapping technological trajectories of the green revolution and the gene revolution from modernization to globalization. Research Policy 32:6, 971-990.

Reij, C. (2014). Re-Greening the Sahel: Linking Adaptation to Climate Change, Poverty Reduction, and Sustainable Development in Drylands. In S. Hecht, K. Morisson \& C. Padoch (eds.): The Social Life of Forests: The Past, Present, and Future of Wooded Landscapes, 303-312. Chicago: University of Chicago Press.

Roesch-McNally, G., A. Basche, J. Arbuckle, J. Tyndall, F. Miguez, T. Bowman, \& R. Clay (2018). The trouble with cover crops: Farmers' experiences with overcoming barriers to adoption. Renewable Agriculture and Food Systems. 33:4, 322-333.

Rosenzweig, S., \& M. Schipanski (2018). Landscape-Scale Cropping Changes in the High Plains: Economic and Environmental Implications. Environmental Research Letters 14:12, 124088.

Schwartz, J. (2020). Gulf of Mexico 'Dead Zone' Will Be Large This Summer, Scientists Predict. The New York Times, 3 June 2020. https://www. nytimes.com/2020/06/03/climate/gulf-of-mexicodead-zone.html.

Statistics Canada (2011). Farm and Farm Operator Data. https://www150.statcan.gc.ca/n1/pub/95-640-x/2011001/p1/p1-05-eng.htm.

Statistics Canada (2014). Average operating revenues and expenses of farms, by farm type. https://www150.statcan.gc.ca/t1/tbl1/en/tv.action?pid=3210007801.

Statistics Canada (2016). Tenure of land owned, leased, rented, crop-shared, used through other arrangements or used by others. https:// www150.statcan.gc.ca/t1/tbl1/en/tv.ac- tion?pid=3210040701.

Statistics Canada (2017). A Portrait of Canadian Farms. https://www150.statcan.gc.ca/n1/pub/11627-m/11-627-m2017010-eng.htm.

Smil, V. (2005). The next 50 Years: Fatal Discontinuities. Population and Development Review 31:2, 201-236.

Union of Concerned Scientists (2017). Turning Soils Into Sponges: How Farmers Can Fight Floods and Droughts. https://www.ucsusa.org/sites/ default/files/attach/2017/08/turning-soils-intosponges-full-report-august-2017.pdf.

UN Food and Agriculture Organization (2020). Conservation Agriculture.http://www.fao.org/ conservation-agriculture/en/.

USDA (2015). Soil Health Literature Summary: Effects of Conservation Practices on Soil Properties in Areas of Cropland. https://www.nrcs.usda.gov/ wps/PA_NRCSConsumption/download?cid=stelprdb1257757\&ext=pdf.

USDA (2018). Chemical, Fertilizer, Labour and Feed Expense by Year. https://www.nass.usda.gov/ Charts_and_Maps/Farm_Production_Expenditures/arms3cht9.php.

USDA (2020a). Farm Sector Income Forecast. https://www.ers.usda.gov/topics/farm-economy/ farm-sector-income-finances/farm-sector-income-forecast/.

USDA (2020b). USDA Outlook Forum. https://www. usda.gov/oce/ag-outlook-forum.

Wang, D. (2020). What is Soil Health and How Can You Build It? https://www.saskatchewan.ca/business/agriculture-natural-resources-and-industry/ agribusiness-farmers-and-ranchers/sask-agnow/crops/crop-production-news/crop-productions-news-2020-issue-1/what-is-soil-health.

Zhou, X., F. Passow, J. Rudek, J. von Fisher, S. Hamburg \& J. Albertson. (2019). Estimation of methane emissions from the U.S. ammonia fertilizer industry using a mobile sensing approach. Elementa: Science of the Anthropocene 7:19, $1-12$. 